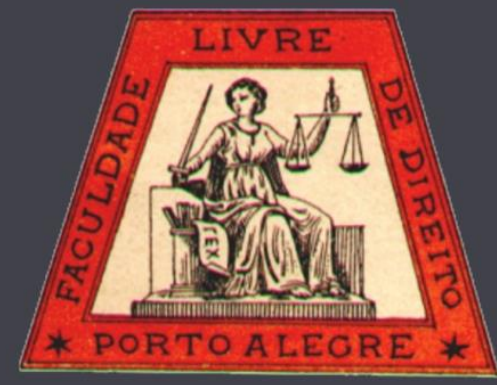

Cidadania ativa na outorga de concessão de serviço público

Active citizenship in the grant of public service concession

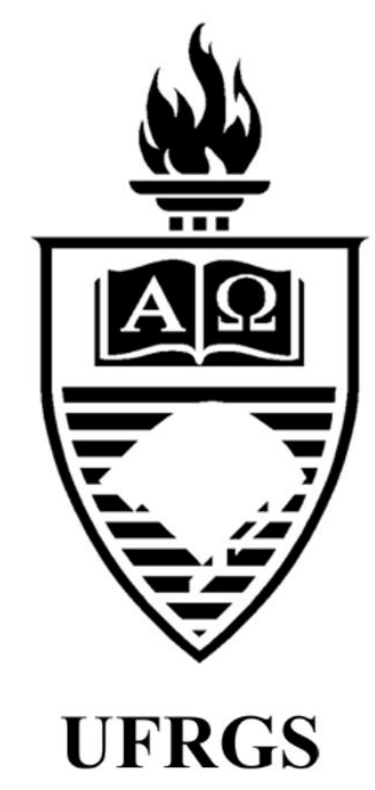

Luiz Eduardo Lemos de Almeida Universidade Federal de Mato Grosso do Sul

Plínio Lacerda Martins

Universidade Federal Fluminense

Revista da Faculdade de Direito da UFRGS

ISSN: 0104-6594 Site http://seer.ufrgs.br/revfacdir

Faculdade de Direito da UFRGS - Rua Riachuelo, 1317 - Centro - Porto Alegre - RS - Brasil

CEP - 90010-271 - Telefone: +55 5133083118 - Site http://www.ufrgs.br/direito/ 


\title{
Cidadania ativa na outorga de concessão de serviço público
}

\author{
Active citizenship in the grant of public service concession
}

Luiz Eduardo Lemos de Almeida*

Plínio Lacerda Martins **

\begin{abstract}
REFERÊNCIA
ALMEIDA, Luiz Eduardo Lemos de; MARTINS, Plínio Lacerda. Cidadania ativa na outorga de concessão de serviço público. Revista da Faculdade de Direito da UFRGS, Porto Alegre, n. 35, p. 85-98, dez. 2016.
\end{abstract}

\section{RESUMO}

O presente artigo aponta as características do Estado Democrático de Direito e dos direitos fundamentais para destacar o dever estatal de proteger e defender o consumidor. Mas ao par desse dever jurídicoconstitucional, aponta também o déficit democrático no ambiente regulatório, a atuação nem sempre satisfatória das agências reguladoras e a vulnerabilidade política do consumidor, com muitas ações voltadas para "os fatores reais de poder", na conhecida lição de Ferdinand Lassale. Frente a esse quadro, o artigo destaca a necessidade de empoderamento da coletividade de consumidores, organização da classe consumerista para o exercício da cidadania ativa no processo administrativo de outorga de concessão e abertura democrática nesse mesmo processo administrativo, isso tudo como forma de contornar problemas causadores da necessidade de proteção e defesa do consumidor.

\section{PALAVRAS-CHAVE}

Outorga de serviço público. Proteção do consumidor. Cidadania ativa e democracia.

\begin{abstract}
The present article points out the characteristics of the democratic constitutional state and of the fundamental rights to highlight the State's duty to protect and defend the consumer. But alongside this legal and constitutional duty, it also points out the democratic deficit in the regulatory environment, the not always satisfactory performance of the regulatory agencies and the consumer's political vulnerability, with many actions aimed at "the real factors of power", in the well-known lesson of Ferdinand Lassalle. Faced with this situation, the article highlights the need for empowerment of the consumer collectivity, organization of the consumerist class for the exercise of active citizenship in the administrative procedure of concession grant, and democratic opening in that same administrative procedure, it all as a way to circumvent the problems causing the need for consumer protection and defense.
\end{abstract}

\section{KEYWORDS}

Grant of Public Service. Consumer Protection. Active citizenship and democracy.

\section{SUMÁRIO}

Introdução. 1 Estado Democrático de Direito e Administração Pública. 2 Direitos fundamentais e proteção do consumidor. 3 Déficit democrático no ambiente regulatório e atuação das agências reguladoras. 4 Vulnerabilidade política do consumidor. 5 Necessidade de empoderamento da coletividade de consumidores, de cidadania ativa e de democracia nos processos administrativos de outorga de concessão. Conclusão. Referências.

\footnotetext{
* Mestrando em Direitos Humanos pela Universidade Federal de Mato Grosso do Sul - UFMS. Especialista em Controle de Constitucionalidade e Direitos Fundamentais pela Pontifícia Universidade Católica do Rio de Janeiro. Especialista em Direito Constitucional pela UNAES - Centro Universitário de Campo Grande.

${ }^{* *}$ Professor na Universidade Federal Fluminense - UFF, Rio de Janeiro, e na Universidade Salgado de Oliveira, Juiz de Fora. Professor convidado na Escola da Magistratura do Rio de Janeiro - EMERJ e na Fundação Getulio Vargas - FGV do Rio de Janeiro. Doutorando em Direito e Sociologia pela Universidade Federal Fluminense. Mestre em Direito pela Universidade Gama Filho em 2001. Especialista em Direito Civil pela Universidade Federal Fluminense em 1998.
} 


\section{INTRODUÇÃO}

A Constituição Federal do Brasil (1988) e legislação ordinária específica formam o arcabouço jurídico destinado à proteção e defesa do consumidor. Juridicamente considerado a parte débil nas relações de consumo ${ }^{1}$, o consumidor tem a ordem constitucional e legal voltada para o resguardo de seus direitos e interesses, cabendo ao Estado o dever de protegê-lo e defendê-lo ${ }^{2}$.

$\mathrm{O}$ dever estatal de proteger e defender os direitos do consumidor também se apresenta na outorga de concessão de serviço público. Na fase administrativa que vai até o momento da celebração e início de vigência de qualquer contrato de concessão de serviço público, o Estado tem por obrigação zelar, proteger e defender os direitos e interesses dos consumidores que irão fruir o serviço concedido.

Nessa fase que antecede o início da prestação do serviço público, quando o processo administrativo de outorga ainda se encontra em curso, o Estado tem papel bifronte. Como Jano ${ }^{3}$, volta-se para duas direções: uma delas é a direção dos interesses da sociedade e dos consumidores que irão tomar o serviço público concedido; a outra, é a direção dos interesses do próprio ente estatal, para aquilo que melhor diz à própria máquina pública.

A questão é que o Estado deixa, não raramente, de cumprir o seu dever. Sem dispensar à coletividade de pessoas e aos consumidores a proteção exigida na legislação, muitas vezes o Estado acaba por celebrar contratos de concessão que se revelam prejudiciais àqueles que tomam e gozam o serviço público concedido. Embora sem participação direta e efetiva na estipulação das

\footnotetext{
${ }^{1}$ Cf. art. $4^{\circ}$, inc. I, do Código de Defesa do Consumidor (Lei n. 8.078/90).

${ }^{2}$ Cf. art. $5^{\circ}$, inc. XXXII, da Constituição Federal.

${ }^{3}$ Deus da mitologia romana com duas faces viradas para direções opostas.
}

condições do contrato de concessão, a sociedade e os consumidores acabam suportando toda a consequência advinda de cláusulas e regras econômicas que lhes são onerosas e prejudiciais, avençadas e estipuladas justamente devido à ausência de cumprimento do dever estatal de proteção.

Invariavelmente, problemas de ordem econômica, criados já no momento da outorga, são detectados somente na fase de execução do contrato de concessão, quando o usuárioconsumidor passa a experimentar constantes e sucessivos prejuízos ${ }^{4}$. Só tardiamente se evidencia, em tais casos, não ter havido proteção e defesa do consumidor na outorga do serviço público.

$\mathrm{O}$ que se pretende, nas linhas que se seguem, é apontar que, apesar de no Brasil se encontrar estabelecido o Estado Democrático de Direito, de haver um catálogo de direitos fundamentais e de existir agências reguladoras voltadas para tecnicamente mediar interesses entre Estado, empresas que disputam o certame em busca da concessão e a sociedade, muitas vezes a legalidade e os direitos fundamentais não são observados, em prejuízo dos consumidores.

Em razão do quadro acima referido, o presente artigo busca mostrar que a cidadania ativa na concessão de serviço público é uma das vias para que a legalidade seja observada, para que equívocos sejam evitados e, ainda, para que os interesses dos consumidores tenham vez e voz no desenho da outorga de serviço público. A cidadania ativa em toda a fase administrativa que precede a celebração de contratos de concessão de serviços públicos pode efetivamente evitar, quando não minimizar, regras e cláusulas

\footnotetext{
${ }^{4}$ A título de exemplo, erro na metodologia para o reajuste da tarifa de energia elétrica em todos os contratos de concessão do serviço público de distribuição de energia elétrica, prejudicial aos usuários-consumidores, foi detectado pelo Tribunal de Contas da União em voto do Min. Benjamin Zymler proferido no Acórdão 2210/2008.
} 
econômicas onerosas e prejudiciais aos usuáriosconsumidores.

\section{ESTADO DEMOCRÁTICO DE DIREITO E ADMINISTRAÇÃO PÚBLICA}

A Constituição Federal de 1988, em seu art. $1^{\circ}$, aponta que a República Federativa do Brasil constitui-se em Estado Democrático de Direito. A compreensão desse conceito de Estado é de significativa importância para se desenvolver a defesa da cidadania ativa na fase administrativa de outorga de concessão de serviço público.

$\mathrm{Na}$ modernidade, o Estado apresentou-se primeiramente como absolutista, com a imposição da sua força política contra qualquer forma particularista de poder. O Estado absolutista monopolizou o poder político e a força militar, transformando-se no único ente capaz de regular o comportamento das pessoas e das forças sociais (Cf. LIMA, 2015, p. 29 e 33).

Com a Revolução Francesa (1789) principalmente, o Estado absolutista cedeu lugar ao Estado de Direito. A ótica que era voltada exclusivamente para o príncipe migra, nesse novo modelo, para os cidadãos (BOBBIO, 2004, p. 58) e faz surgir o problema dos limites do poder (BOBBIO, 2010, p. 93-94). O Estado caracteriza-se, a partir de então, como aquele submetido ao direito, controlado pela lei como expressão da vontade geral (COELHO, 2008, p. 64), com a pretensão de que o âmbito estatal seja presidido por normas jurídicas (VERDÚ, 2007, p. 1). Cuida-se do Estado que se submete às leis criadas pelo próprio Estado.

O Estado de Direito, com sua característica essencial de a lei regular toda a atividade estatal, se mantém desde o fim do absolutismo sob variadas espécies, isto é, Estado Liberal de Direito, Estado Social de Direito e Estado Democrático de Direito (VERDÚ, 2007, p. 137). No ponto, a considerações de Pablo Lucas Verdú aclaram:

Quero dizer que cada uma dessas espécies foi estabelecida ou foi objeto de tentativas de estabelecimento por meio da luta contra estruturas de poder contrárias: o Estado Liberal de Direito em relação ao Antigo Regime; o Estado Social de Direito contra o individualismo e absenteísmo do Estado Liberal; o Estado Democrático de Direito, que forceja contra as estruturas sociopolíticas do modelo anterior: resquícios individualistas, neocapitalismo opressor, sistema estabelecido privilegiado. (VERDÚ, 2007, p. 137).

A Constituição Federal de 1988, seguindo passo a esse evolver das formas de Estado, inovou na ordem jurídico-constitucional ao prescrever o Estado Democrático de Direito para a República Federativa do Brasil. Democracia, ordem legal e transformação social são as marcas dessa espécie de Estado de Direito que é o Estado Democrático de Direito vigente no Brasil. Seu objetivo é, sobretudo, a igualdade transformadora com fundamento na lei, de modo que a legislação não se presta mais somente para restringir ou promover a atuação estatal, como, respectivamente, no Estado Liberal de Direito e no Estado Social de Direito.

O que o Estado Democrático de Direito impõe é a transformação da realidade, com a ordem jurídica servindo de instrumental para a realização e concretização da igualdade com vistas a uma sociedade mais justa e equânime. Esse formato de Estado, importante registrar, tem por princípios: a) a constitucionalidade; b) a organização democrática da sociedade; c) o sistema de direitos fundamentais individuais e coletivos; d) a justiça social; e) a igualdade; f) a divisão de poderes ou funções; g) a legalidade; h) a segurança e a certeza jurídicas. (Cf. STRECK; MORAIS, 2014, p. 98-100).

Além de seus princípios, o Estado Democrático de Direito brasileiro tem como fundamento, dentre outros, a dignidade da pessoa humana. Valor jurídico supremo, ela, a dignidade da pessoa humana, está no art. $1^{\circ}$, inc. III, da Constituição Federal de 1988 como princípio que reconhece cada ser humano como merecedor de respeito e consideração, implicando um complexo de direitos e de deveres fundamentais que a garantam (SARLET, 
2010, p. 70).

O formato atual do Estado brasileiro, com seus princípios e fundamentos, importa em reflexos sobre sua ordem jurídica interna. Com efeito, a ordem jurídica brasileira como um todo deve ser entendida como meio de servir aos propósitos do Estado Democrático de Direito, com a constitucionalização do direito exercendo papel de relevo nisso, porquanto ela, a constitucionalização, faz com que os mais diversos ramos do direito encontrem seu fundamento nas normas constitucionais. Há “[...] perda de importância dos chamados princípios gerais do direito em favor das normas constitucionais [...]" e "[...] o eixo essencial da ordem jurídica deixa de ser a lei e passa a ser a constituição [...]" (SILVA, 2011, p. 49).

Reflexos também há sobre instituições administrativas. Estas não estão alheias à constitucionalização nem podem se desviar do Estado Democrático de Direito, de seus princípios e de seus fundamentos. A Constituição Federal de 1988 alterou sobremaneira, a exemplo do ocorrido em tantas outras áreas jurídicas (como o direito civil, p.ex.), o direito administrativo até então vigente.

Com efeito, aquele direito administrativo consubstanciado no poder hierárquico pleno, no poder de polícia não dialógico com os direitos fundamentais, na supremacia ilimitada e absoluta do interesse público sobre o interesse privado, enfim, o direito administrativo que o EstadoAdministração podia tudo, na atualidade cuida-se apenas de referência histórica capaz de demonstrar a sua evolução em nosso país.

Diante de uma Lei Maior permeada pela dignidade da pessoa humana, por princípios e regras com valores jurídicos voltados para a realização dos direitos fundamentais - estes com papel central na nossa $\mathrm{CF} / 88$-, o EstadoAdministração perdeu por completo seu viés monarca e absolutista para pautar-se, em definitivo, pela governança, pela tomada de decisões ótimas, pela busca incessante dos objetivos da República Federativa do Brasil, dos princípios do Estado Democrático de Direito e da afirmação dos direitos fundamentais:

Além da parte introdutória da Constituição, onde se afirmam os seus princípios fundamentais, em vários outros dispositivos se revela a preocupação com determinados valores a serem observados no desempenho da função estatal e, dentro desta, da função administrativa a cargo da Administração Pública. Esta já não está mais submetida apenas à lei, em sentido formal, mas a todos os princípios que consagram valores expressos ou implícitos na Constituição, relacionados com a liberdade, igualdade, segurança, desenvolvimento, bem-estar e justiça. (DI PIETRO, 2001, p. 46).

Em verdade, a administração pública moderna, de forma geral, exige que o administrador atue e escolha bem. A escorreita gestão da coisa e do interesse públicos cuida-se de dever imposto ao administrador em decorrência de os administrados disporem do direito fundamental à boa administração pública (Cf. FREITAS, 2009, p. 9). E boa administração pública só pode ser aquela que prime pelos objetivos da República Federativa do Brasil e pelos princípios do Estado Democrático de Direito.

A compreensão do significado, dos princípios e dos fundamentos do Estado Democrático de Direito é importante porque a não apuração, consideração e decisão sobre a vontade e os anseios da sociedade e dos consumidores quanto a serviço público destacado para outorga de concessão importa em negação e desconsideração do próprio Estado Democrático de Direito.

\section{DIREITOS FUNDAMENTAIS E PROTEÇÃO DO CONSUMIDOR}

Os direitos fundamentais, intimamente relacionados aos Direitos Humanos (Cf. SARLET, 2009, p. 32), são vinculantes e não estão à disposição do legislador ordinário, do administrador público ou do julgador, isso devido à supremacia do texto constitucional, onde se situam. Quando legitimamente promulgada, a Constituição de um determinado Estado advém da soberania popular (CANOTILHO, 1999, p. 70-78) que permanece 
e se faz sentir no sistema jurídico-político por meio da proeminência do contido no texto constitucional. As disposições constitucionais posicionam-se hierarquicamente superiores às disposições infraconstitucionais e à vontade do processo político. É o que se denomina de supremacia da Constituição (COELHO, 2008, p. 14-17).

É importante ter presente que entre Constituição, Estado de Direito e direitos fundamentais há uma íntima e indissociável vinculação. Os direitos fundamentais integram o Estado constitucional, sendo a concretização daqueles a tarefa permanente deste último (SARLET, 2009, p. 58-59).

Os direitos fundamentais, designados na doutrina jurídica como de primeira dimensão, apresentam-se como garantias dos indivíduos frente ao Estado para a contenção do poder, para a eliminação de abusos, isso em prol da liberdade individual (DIMOULIS; MARTINS, 2007, p. 54). Além da primeira dimensão, há as chamadas segunda e terceira dimensões de direitos fundamentais (SILVEIRA; ROCASOLANO, 2010, p. 172-180). De forma sintética, com o risco de reducionismo, a segunda dimensão de direitos fundamentais diz com as necessidades humanas, com os direitos econômicos, sociais e culturais. Já a terceira dimensão de direitos fundamentais versa sobre a solidariedade e o dever de cooperação em favor do ser humano. Na lição de Willis Santiago Guerra Filho essas dimensões estão resumidamente assim anotadas:

A primeira geração é aquela em que aparecem as chamadas liberdades públicas, "direitos de liberdade" (freiheitsrechte), que são direitos e garantias dos indivíduos a que o Estado omita-se de interferir em sua esfera juridicamente intangível. Com a segunda geração surgem direitos sociais a prestações pelo Estado (leistungrechte) para suprir carências da coletividade. Já na terceira geração concebe-se direitos cujo sujeito não é mais o indivíduos nem a coletividade, mas sim o próprio gênero humano, como é o caso do direito à higidez do meio ambiente e do direito dos povos ao desenvolvimento. (GUERRA FILHO, 2000, p. 47)

Desse modo, direitos fundamentais apresentam-se sim como garantias dos indivíduos frente ao Estado para a contenção do poder, para a eliminação de abusos e em prol da liberdade individual, mas apresentam-se também como garantias de direitos econômicos, sociais e culturais às pessoas, além de serem de garantias de solidariedade e de dever de cooperação em favor do ser humano.

Em todas as suas dimensões, os direitos fundamentais possuem um sentido subjetivo e outro objetivo. Isso é particularmente importante à medida que o primeiro sentido (subjetivo) diz com aqueles que titularizam os direitos fundamentais, enquanto que o segundo (objetivo) diz com o Estado enquanto destinatário dos direitos fundamentais e que nessa condição tem de cumprir seu dever de garanti-los e assegurálos aos indivíduos, posto formarem os direitos fundamentais um conjunto de valores básicos e fins diretivos dos poderes públicos (SARLET, 2009, p. 143).

É sob a perspectiva objetiva que o Estado tem o dever de proteger e defender, por exemplo, os direitos do consumidor, porque assim está consignado no art. $5^{\circ}$, inc. XXXII, da Constituição Federal. Assim como o consumidor é titular desse direito, isso sob a perspectiva subjetiva dos direitos fundamentais, o Estado é seu destinatário e sob a perspectiva objetiva dos direitos fundamentais cabe-lhe atuar para cumprir com o seu dever constitucional. Exatamente por isso é que a doutrina Claudia Lima Marques apregoa o seguinte:

Promover significa assegurar afirmativamente que o Estado-Juiz, que o Estado-Executivo e o EstadoLegislativo realizem positivamente a defesa, a tutela dos interesses destes consumidores. É um direito fundamental (direito humano de nova geração, social e econômico) a uma prestação protetiva do Estado, a uma atuação positiva do Estado, por todos os seus poderes: Judiciário, Executivo, Legislativo. (MARQUES, 2008, p. 25). 
Inegável que a defesa do consumidor tem que se dar de forma efetiva nos processos de concessão de serviço público, pois “"...] direitos fundamentais vinculam os órgãos administrativos em todas as suas formas de manifestação e atividades [...]" (SARLET, 2013, p. 195). E essa vinculação, importante registrar, não pode ser tangenciada pelo administrador, nas outorgas de concessão de serviço público, simplesmente com a invocação do interesse público.

Com efeito, esse ponto, por demais importante, encontra na doutrina moderna a seguinte posição que reputamos acertada: "A fórmula que postula a necessária e inconteste primazia do interesse público sobre o particular é uma simplificação errônea e frequente do problema que existe entre o interesse público e os direitos fundamentais." (ABBOUD, 2011, p. 61-110). Pode haver restrição a direitos fundamentais, mas simplesmente "[...] a decretação do 'interesse público' é um ato arbitrário do Estado que, como um Midas, coloca o selo de 'público' em tudo que toca." (ABBOUD, 2011, p. 61-110)

O que o Estado tem de fazer é demonstrar satisfatoriamente que ao outorgar concessão de serviço público para exploração por empresa privada apura, considera e decide efetivamente acerca da vontade e dos anseios da sociedade e dos consumidores, cumprindo com o sentido objetivo dos direitos fundamentais de garantir e assegurar aos indivíduos aquilo que com luta, debates e democracia restou consignado na Constituição Federal e na legislação.

Finaliza-se a presente seção, importante enquanto destaque jurídico-formal dos direitos fundamentais, com a preocupação acerca da possibilidade de falhanço no cumprimento da ordem constitucional de se proteger e defender o consumidor nos processos administrativos de outorga de concessão de serviço público. Essa preocupação, real e não apenas hipotética, aumenta com o que vai lançado nas duas seções abaixo, como logo se verá.

\section{DÉFICIT DEMOCRÁTICO NO AMBIENTE REGULATÓRIO E ATUAÇÃO DAS AGÊNCIAS REGULADORAS}

As seções anteriores (1 e 2) descrevem formalmente o Estado de Democrático de Direito e os direitos fundamentais que os indivíduos titularizam e que o ente estatal é destinatário. Trata do mundo dever-ser segundo o direito posto. Isso não significa, no entanto, que a realidade seja correspondente ao que é juridicamente prescrito, como já anunciado no final da seção precedente. De alguma forma, isso será tratado aqui e também na seção seguinte a fim de evidenciar a necessidade de empoderamento da coletividade de consumidores, de cidadania ativa e de democracia nos processos administrativos de outorga de concessão.

$\mathrm{Na}$ doutrina pátria há concordância de existir no ordenamento jurídico brasileiro a exigência de um Estado eficiente e que se conduza por escolhas legítimas (FREITAS, 2009; MIRAGEM, 2011; BINENBOJM, 2014). No tocante à concessão de serviço público, a eficiência administrativa e as escolhas legítimas feitas pelo Estado passam necessariamente pela consideração, proteção e defesa dos interesses e direitos dos consumidores que irão gozar e custear o serviço concedido. $\mathrm{O}$ dever fundamental do Estado em promover a proteção e defesa do consumidor tem de ser cumprido para se falar em eficiência administrativa e escolhas legítimas.

No entanto, é fato que a concessão de serviço público cuida-se de matéria complexa envolvendo superestrutura sob todos os ângulos, com numerários elevados, contratos de difícil intelecção e alta tecnicidade no desempenho das 
atividades das empresas - que os cidadãos e os consumidores naturalmente se veem afastados das discussões e deliberações. Suas informações e seu poder de argumentação são, invariavelmente, muito inferiores aos reunidos pelas empresas que disputam o certame e pelo poder concedente. Há assimetria de informação e de poder e há, também, déficit democrático no ambiente regulatório. Na doutrina especializada de Conrado Hübner Mendes colhe-se a seguinte observação:

Notamos que a esfera da relação com maior carência de representatividade é, definitivamente, a parcela dos usuários. A participação destes, ressalte-se, é extremamente dificultosa, eis que são leigos nos assuntos eminentemente técnicos postos na pauta decisória da agência. (MENDES, 2006, p. 132)

Para compensar essa deficiência informacional, argumentativa e participativa dos cidadãos em geral e dos usuários-consumidores em específico, as agências reguladoras têm o dever de proteger os integrantes dessas aludidas classes, considerados hipossuficientes. Ao menos em tese, as agências de regulação em geral formam o lado estatal com perfil técnico especializado e expertise suficiente para tratar à altura com poder concedente, empresas que participam do processo licitatório e coletividade de usuários-consumidores, sempre equalizando e regulando os interesses dessa tríade.

No entanto, nem sempre as agências regulatórias são autônomas e independentes, como deveriam ser. Muitas delas não dispõem de recursos necessários para atuação eficaz e ficam sujeitas aos poderes e interesses dos entes regulados ou mesmo sujeita aos poderes e interesses políticos.

Diante de agência de regulação fraca, que não goze de plena autonomia e independência, pode haver o risco de captura do órgão por parte dos entes regulados, fenômeno descrito doutrinariamente sob a denominação de “[...] captura por contaminação de interesses. Esta se manifesta com a assunção pelo órgão regulador dos valores e interesses do regulado, como se fossem os interesses gerais da coletividade [...]" (MARQUES NETO, 2006, p. 89, grifo do autor). Até nos Estados Unidos, berço da regulação e com agências verdadeiramente autônomas e independentes, esse fenômeno não é ignorado e ronda realmente a atividade regulatória. É o que informa o estudo de Conrado Hubner Mendes, a saber:

Entre os anos de 1965 e 1985 defrontou-se o sistema regulatório americano com um problema que desvirtuou as finalidades da regulação desvinculada do poder político: a captura das agências reguladoras pelos agentes econômicos regulados. Explique-se: os agentes privados, com seu colossal poder econômico e grande poder de influência, diante de entes reguladores que dispunham de completa autonomia perante o poder político, não encontraram dificuldades para implantar um mecanismo de pressão que acabasse por quase que determinar o conteúdo da regulação que iriam sofrer. Os maiores prejudicados, por consequência, foram os consumidores. (MENDES, 2006, p. 121)

Ademais, agência de regulação fraca, que não goza de plena autonomia e independência, pode sofrer o risco de captura também por parte do poder político, “[...] traduzida no atrelamento da atividade regulatória aos interesses conjunturais do bloco do poder, às vicissitudes eleitorais [...]", como destaca Floriano Azevedo Marques Neto (2006, p. 90).

$\mathrm{O}$ déficit democrático no ambiente regulatório e a possível atuação insuficiente de agências regulatórias colocam em xeque, sem dúvida alguma, um Estado eficiente e que se conduza por escolhas legítimas, com efetiva proteção e defesa dos interesses e direitos dos consumidores que irão gozar e custear o serviço concedido. Além disso, abusos sobre a vulnerabilidade do consumidor podem agravar esse quadro, como se verá a seguir. 


\section{VULNERABILIDADE POLÍTICA DO CONSUMIDOR}

A proteção jurídica do consumidor decorre da sua reconhecida vulnerabilidade. O Código de Defesa do Consumidor presume, de forma absoluta, essa característica do destinatário final de produtos e serviços em seu art. $4^{\circ}$, inc. I. A vulnerabilidade, ensina-nos Cláudia Lima Marques, distingue-se em quatro grandes espécies: vulnerabilidade técnica; vulnerabilidade jurídica; vulnerabilidade fática; e vulnerabilidade informacional (MARQUES, 2006, p. 320).

Além dessas espécies, Paulo Valério Dal Pai Moraes identifica outras tantas, como a vulnerabilidade política ou legislativa (MORAES, 2009, p. 155). Destaca seu magistério que, em prejuízo do consumidor, muitas ações políticas e legislativas são adotadas em prol daqueles que formam "os fatores reais de poder", na conhecida lição de Ferdinand Lassale. A vontade da maioria é deixada de lado para se atender interesses de grupos, de alguns, de um particular qualquer ou mesmo de um ente estatal com ótica apenas para o interesse público secundário, i.e., aquele interesse, como pontua Luís Roberto Barroso, “[...] da pessoa jurídica de direito público que seja parte em determinada relação jurídica [...]", podendo ser “[...] identificado como interesse do erário, que é o de maximizar a arrecadação e minimizar as despesas [...]" (BARROSO, 2009, p. 71). Isso se dá em razão de que:

[...] cada vez mais as discussões, principalmente jurídicas, pendem para a proteção dos valores econômicos ao invés dos valores sociais, estabelecendo hierarquia odiável e aumentando a vulnerabilidade política que macula os consumidores, quando, em realidade, deveriam estar os sistemas mesclados para o atendimento das necessidades de todos os homens, e não somente de alguns. (MORAES, 2009, p. 164).
Esse tipo de vulnerabilidade pode perfeitamente atingir usuários-consumidores de serviço público quando do processo administrativo de outorga de concessão de serviço público, privilegiando-se interesses de empresas que disputam o certame e interesses estatais em detrimento de interesses da coletividade de consumidores.

\section{NECESSIDADE DE EMPODERAMENTO DA COLETIVIDADE DE CONSUMIDORES, DE CIDADANIA ATIVA E DE DEMOCRACIA NOS PROCESSOS ADMINISTRATIVOS DE OUTORGA DE CONCESSÃO}

O Estado Democrático de Direito, fundado na dignidade da pessoa humana e com um catálogo de direitos e garantias fundamentais, tem de se apresentar no interior da formatação constitucional de uma administração pública que não se pauta mais sob a relação de poder entre o Estado e os administrados, mas sim sob uma relação de gestão com vistas aos fins sociais (MIRAGEM, 2011, p. 29). Nisso se insere a defesa do consumidor enquanto direito fundamental dos indivíduos (dimensão subjetiva dos direitos fundamentais) e enquanto dever estatal (dimensão objetiva dos direitos fundamentais).

O déficit democrático no ambiente regulatório, a possível atuação insuficiente de agências regulatórias e a vulnerabilidade política do consumidor, no entanto, indicam que para haver efetiva relação de gestão com vistas aos fins sociais na atuação estatal tem de haver, necessariamente, o protagonismo da coletividade de consumidores. Tem de haver o real empoderamento da coletividade de consumidores para que seus anseios cheguem às instâncias competentes para efetiva avaliação e decisão administrativas.

Com efeito, para que os direitos 
fundamentais e o Estado Democrático de Direito não se reduzam a discursos, com práticas políticas a cometer ou tolerar suas violações, os movimentos sociais em defesa dos direitos humanos, aqui tidos como aqueles que "[...] procuram, em suas ações, desenvolver seu protagonismo político, refazendo suas relações com o Estado, a fim de ampliar os espaços de emancipação [...]" (VIOLA, 2008, p. 26), apresentam-se como um dos meios de os próprios consumidores reivindicarem e fazerem valer seus direitos.

As associações de defesa do consumidor parecem-nos variações de movimentos sociais enquanto instrumentos da sociedade civil voltados para reivindicação de ampliação do espaço democrático, para exigência de observância da legalidade e para postulação de realização de justiça no processo administrativo de outorga de concessão. Não são meios que visam o assembleísmo ou a sobreposição ao papel estatal, mas meios de cidadania ativa em busca de emancipação social. A respeito desse ponto, pertinente se apresenta a seguinte advertência de Bruno Miragem:

Não se trata de anseio de usuários ou cidadãos decidirem, mediante deliberação majoritária, questões cujo adequado tratamento exige especialidade e conhecimento técnico, o que evidentemente não seria recomendável. Trata-se, contudo, de conferir-se maior seriedade e protagonismo aos canais de participação junto aos órgãos reguladores, inclusive aqueles já previstos na legislação, de modo a estabelecer para seus dirigentes um dever de conhecimento e manifestação sobre as ponderações formuladas por intermédio destes mecanismos, o que por si eleva seu nível de responsabilidade pelas decisões adotadas e amplia a transparência dos processos de tomada de decisão no âmbito da atividade regulatória do Estado. (MIRAGEM, 2011, p. 92).

$\mathrm{O}$ que, em verdade, se afigura recomendável e frutífero é o empoderamento da coletividade de consumidores por meio da formação e atuação de associações de defesa dos consumidores, o que pode contribuir com as discussões e conferir legitimidade às decisões tomadas. Mas tais associações devem atuar no mesmo nível de poder do Estado e das empresas que disputam a concessão de serviço público. Não deve haver assimetria de poder. Uma proposta para o fortalecimento da coletividade de consumidores é assim lançada por Bruno Miragem:

Uma iniciativa que objetiva melhorar o nível de
participação dos usuários por intermédio dos canais
atualmente existentes (audiências e consultas
públicas) é a que assegura - por intermédio de
auxílio estatal - certo grau de assessoramento
técnico que permita aos usuários em geral, por suas
organizações representativas, aprofundar o exame
especializado dos temas objeto de debate público,
diminuindo a assimetria informativa entre agentes
econômicos e usuários quanto a aspectos técnicos
relativos ao setor regulado. (MIRAGEM, 2011, p.
118)

Mas ao par da formação e atuação de associações de defesa dos consumidores deve se dar a ampliação democrática no processo administrativo de outorga de concessão. De nada adianta a formação de movimentos sociais em prol da coletividade de consumidores e de mecanismos de eliminação, ou ao menos de redução, da assimetria de poder e informacional se o poder público laborar com a democracia formal. Em verdade, o Estado tem por obrigação atuar mediante a promoção de democracia substantiva e afastar-se da democracia formal, buscando uma relação de gestão com vistas aos fins sociais, ainda que tenha de ampliar as zonas de contato com a sociedade civil para além das audiências públicas, como previsto na legislação de regência (art. 39 da Lei n. 8.666/93), sujeitando-se a fiscalizações em oportunidade outras.

A defesa do consumidor enquanto direito fundamental dos indivíduos (dimensão subjetiva dos direitos fundamentais) e enquanto dever estatal (dimensão objetiva dos direitos 
fundamentais) requer, em tese, o necessário fortalecimento da coletividade de consumidores nas tratativas e nos procedimentos voltados para a outorga de serviço público. Somente assim podem ser contornados os problemas de possibilidade de falhanço no cumprimento da ordem constitucional de se proteger e defender o consumidor nos processos administrativos de outorga de concessão de serviço público.

Todos os mecanismos de defesa do consumidor e de cidadania ativa acima referidos pressupõem, na nossa ótica, amplo desenvolvimento da educação, tanto a geral, como preconizada no art. 205 da Constituição Federal, quanto a para o consumo, como estatuída pelo art. $4^{\circ}$, inc. IV, do Código de Defesa do Consumidor. Sem educação não há como formar consciência acerca de direitos consumeristas, de reunir interesses comuns em associações, de exigir protagonismo em processos administrativos de outorga de serviço público, de reclamar maior espaço democrático nesses procedimentos, de reclamar assessoria técnica por parte do Estado para eliminar assimetria de poder e informacional, enfim, não há como realizar plenamente a cidadania, tal como ditada pelo art. $1^{\circ}$ da $\mathrm{CF} / 88$ como um dos fundamentos da República Federativa do Brasil.

\section{CONCLUSÃO}

O dever estatal de proteger e defender os direitos do consumidor se apresenta na outorga de concessão de serviço público. O Estado tem por obrigação zelar, proteger e defender os direitos e interesses dos consumidores que irão fruir o serviço público concedido.

O Estado deixa de cumprir seu dever e não dispensa à coletividade de pessoas e aos consumidores a proteção exigida na legislação toda vez que celebra contratos de concessão que se revelam prejudiciais àqueles que tomam e gozam o serviço público concedido. Essa falha estatal se dá, basicamente, pelos seguintes fatores, que podem se apresentar reunidos ou separadamente:

a) possibilidade de a proteção do consumidor ser meramente formal e discursiva;

b) cuidar-se a concessão de serviço público de matéria complexa da qual os cidadãos e os consumidores naturalmente se veem afastados das discussões e deliberações;

c) as informações e o poder de argumentação dos consumidores serem muito inferiores aos reunidos pelas empresas que disputam o certame e pelo poder concedente;

d) haver assimetria de informação e de poder e, também, déficit democrático no ambiente regulatório;

e) agências regulatórias nem sempre autônomas e independentes, com recursos necessários para atuação eficaz, mas sujeitas aos poderes e interesses dos entes regulados ou mesmo aos poderes e interesses políticos;

f) vulnerabilidade política ou legislativa do consumidor, com muitas ações adotadas em prol daqueles que formam "os fatores reais de poder", relegando-se a segundo plano a vontade da maioria para atendimento de interesses de grupos, de alguns, de um particular qualquer ou mesmo de um ente estatal com ótica apenas para o interesse público secundário.

O empoderamento da coletividade de consumidores, por meio da formação e atuação de associações de defesa dos consumidores no mesmo nível de poder do Estado e das empresas que disputam a concessão de serviço público, pode contribuir para a proteção do consumidor por meio de discussões e da legitimidade nas decisões tomadas em processos administrativos de outorga de serviço público.

A ampliação democrática no processo administrativo de outorga de concessão tem de ocorrer para que a formação de movimentos 
sociais em prol da coletividade de consumidores alcance a eliminação, ou ao menos de redução, da assimetria de poder e informacional. O Estado tem por obrigação atuar mediante a promoção de democracia substantiva e afastar-se da democracia formal, buscando uma relação de gestão com vistas aos fins sociais.

Todos os mecanismos de defesa do consumidor e de cidadania ativa referidos no presente artigo pressupõem o amplo desenvolvimento da educação, tanto a em geral, como preconizada no art. 205 da Constituição Federal, quanto a para o consumo, como estatuída pelo art. $4^{\circ}$, inc. IV, do Código de Defesa do Consumidor. Sem educação não há como realizar plenamente a cidadania, tal como ditada pelo art. $1^{\circ}$ da $\mathrm{CF} / 88$ como um dos fundamentos da República Federativa do Brasil.

\section{REFERÊNCIAS}

ABBOUD, Georges. O mito da supremacia do interesse público sobre o privado: a dimensão constitucional dos direitos fundamentais e os requisitos necessários para se autorizar restrição a direitos fundamentais. Revista dos Tribunais, São Paulo, v. 907, p. 61-97, mai. 2011.

BARROSO, Luís Roberto. Curso de direito constitucional contemporâneo: os conceitos fundamentais e a construção do novo modelo. São Paulo: Saraiva, 2009.

BINENBOJM, Gustavo. Uma teoria do direito administrativo: direitos fundamentais, democracia e constitucionalização. Rio de Janeiro: Renovar, 2014.

BOBBIO, Norberto. A era dos direitos. Rio de Janeiro: Elsevier, 2004.

2010.

Estado, governo, sociedade: para uma teoria geral da política. São Paulo: Paz e Terra,

CANOTILHO, J. J. Gomes. Direito constitucional e teoria da constituição. Coimbra: Almedina, 1999.

COELHO, Inocêncio Mártires. Origens, desenvolvimento histórico e modelos de estado de direito. In: MENDES, Gilmar Ferreira et al. Curso de direito constitucional. Saraiva: 2008.

DI PIETRO, Maria Sylvia Zanella. Discricionariedade administrativa na Constituição de 1988. São Paulo: Atlas, 2001.

DIMOULIS, Dimitri; MARTINS, Leonardo. Teoria geral dos direitos fundamentais. São Paulo: Revista dos Tribunais, 2007.

FREITAS, Juarez. Discricionariedade administrativa e o direito fundamental à boa administração pública. São Paulo: Malheiros, 2009.

GUERRA FILHO, Willis Santiago. Teoria processual da constituição. São Paulo: Celso Bastos/IBDC, 2000.

LIMA, Danilo Pereira. Constituição e poder: limites da política no estado de direito. Porto Alegre: Livraria do Advogado, 2015. 
MARQUES, Cláudia Lima. Contratos no Código de Defesa do Consumidor: o novo regime das relações contratuais. $5^{\text {a }}$ ed. São Paulo: Revista dos Tribunais, 2006.

MARQUES, Claudia Lima et al. Manual de direito do consumidor. São Paulo: Editora Revista dos Tribunais, 2008.

MARQUES NETO, Floriano Azevedo. A nova regulação estatal e as agências independentes. In: SUNDFELD, Carlos Ari (Coordenador). Direito administrativo econômico. São Paulo: Malheiros, 2006.

MENDES, Conrado Hübner. Reforma do estado e agências reguladoras: estabelecendo os parâmetros de discussão. In: SUNDFELD, Carlos Ari (Coordenador). Direito administrativo econômico. São Paulo: Malheiros, 2006.

MIRAGEM, Bruno. A nova administração pública e o direito administrativo. São Paulo: Revista dos Tribunais, 2011.

MORAES, Paulo Valério Dal Pai. Código de defesa do consumidor: o princípio da vulnerabilidade no contrato, na publicidade, nas demais práticas comerciais: interpretação sistemática do direito. Porto Alegre: Livraria do Advogado, 2009.

SARLET, Ingo Wolfgang. A eficácia dos direitos fundamentais: uma teoria geral dos direitos fundamentais na perspectiva constitucional. Porto Alegre: Livraria do Advogado, 2009.

Dignidade da pessoa humana e direitos fundamentais. Porto Alegre: Livraria do Advogado, 2010, p. 70.

SILVA, Virgílio Afonso da. A constitucionalização do direito: os direitos fundamentais nas relações entre particulares. São Paulo: Malheiros, 2011.

SILVEIRA, Vladimir Oliveira da. ROCASOLANO, Maria Mendez. Direitos humanos: conceitos, significados e funções. São Paulo: Saraiva, 2010.

STRECK, Lênio Luiz; BOLZAN DE MORAES, José Luis. Ciência política \& teoria do Estado. Porto Alegre: Livraria do Advogado, 2014.

VIOLA, Solon Eduardo Annes. Direitos humanos e democracia no Brasil. São Lepoldo: Unisinos, 2008.

VERDÚ, Pablo Lucas. A luta pelo estado de direito. Rio de Janeiro: Forense, 2007.

Recebido em: 27/11/2016

Aceito em: 31/12/2016 
